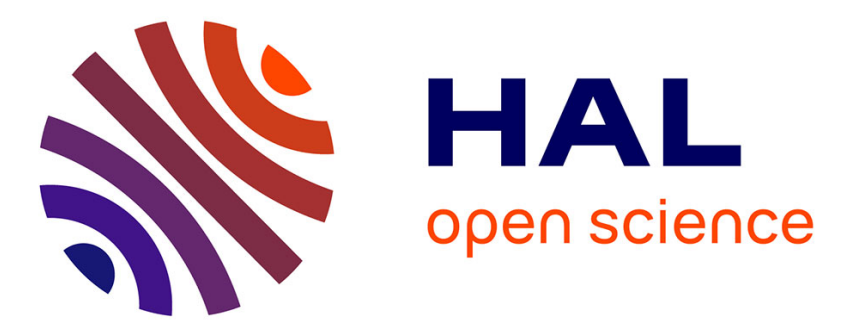

\title{
Hyperspectral Estimation Methods for Chlorophyll Content of Apple Based on Random Forest
}

Haojie Pei, Changchun Li, Haikuan Feng, Guijun Yang, Mingxing Liu, Zhichao $\mathrm{Wu}$

\section{- To cite this version:}

Haojie Pei, Changchun Li, Haikuan Feng, Guijun Yang, Mingxing Liu, et al.. Hyperspectral Estimation Methods for Chlorophyll Content of Apple Based on Random Forest. 11th International Conference on Computer and Computing Technologies in Agriculture (CCTA), Aug 2017, Jilin, China. pp.194-207, 10.1007/978-3-030-06179-1_20 . hal-02111543

\section{HAL Id: hal-02111543 \\ https://hal.inria.fr/hal-02111543}

Submitted on 26 Apr 2019

HAL is a multi-disciplinary open access archive for the deposit and dissemination of scientific research documents, whether they are published or not. The documents may come from teaching and research institutions in France or abroad, or from public or private research centers.
L'archive ouverte pluridisciplinaire HAL, est destinée au dépôt et à la diffusion de documents scientifiques de niveau recherche, publiés ou non, émanant des établissements d'enseignement et de recherche français ou étrangers, des laboratoires publics ou privés.

\section{(c)(1)}

Distributed under a Creative Commons Attribution| 4.0 International License 


\title{
Hyperspectral Estimation Methods for Chlorophyll Content of Apple Based on Random Forest
}

Haojie Pei $i^{1,2,3,4,5}$, Changchun $\mathrm{Li}^{5^{*}}$, Haikuan Feng ${ }^{1,2,3,4(\bowtie)}$, Guijun Yang ${ }^{1,2,3,4}$, Mingxing Liu ${ }^{1,2,3,4,5}$, Zhichao Wu ${ }^{1,2,3,4,5}$

${ }^{1}$ Key Laboratory of Quantitative Remote Sensing in Agriculture of Ministry of Agriculture P. R. China, Beijing Research Center for Information Technology in Agriculture, Beijing 100097, China

\{xmljphj, fenghaikuan123,wZC032018, guijun.yang\}@163.com,

liumingxingreal@126.com

${ }^{2}$ National Engineering Research Center for Information Technology in Agriculture, Beijing, 100097, China

${ }^{3}$ Key Laboratory for Information Technologies in Agriculture, the Ministry of Agriculture, 100097, China

${ }^{4}$ Beijing Engineering Research Center of Agricultural Internet of Things, Beijing, 100097, China

${ }^{5}$ School of Surveying and Land Information Engineering, Henan Polytechnic University, Jiaozuo 454000, China

lichangchun610@126.com

\begin{abstract}
Chlorophyll content is a good indicator of fruit tree nutrition stress, photosynthesis, and another physiological state. 10 vegetation indices were selected and used as input variables of RF model, the number of input variables was gradually increased from 1 to 10. The modeling accuracy of 10 RF models with vegetation indices was compared. Finally, the accuracy of 2 estimation models, the RF model with the original spectrum, and the RF optimal model with vegetation indices were established and compared. The result, For modeling accuracy of 2 models, the $R^{2}$ of four models are 0.527 and 0.609 , and the RMSE of 2 models are 8.728 and $7.930 \mu \mathrm{g} / \mathrm{cm}^{2}$, respectively. For validation accuracy of 2 models, $R^{2}$ of 2 models is 0.411 and $0.843, R M S E$ is 14.455 and 11.034 $\mu \mathrm{g} / \mathrm{cm}^{2}$, respectively. The result showed, (1) the accuracy of RF model with vegetation indices is higher than the other model. (2) The RF model with vegetation indices can estimate the chlorophyll content of apple leaves more accurately and it had the potential for estimating chlorophyll content of apple leaf. And it provides a new method for the accurate estimation of chlorophyll of apple leaves.
\end{abstract}

Keywords: apple leaf, hyperspectral, chlorophyll, RF

\section{Introduction}

Chlorophyll content is an important biochemical parameter in the growth process of fruit trees. It is instructive for the photosynthetic capacity, developmental stage and nutritional status of fruit trees. And it is the indicator that the fruit trees are affected by environmental stress and disease indicator[1-2]. It is very important to use the hyperspectral extraction of leaf chlorophyll content information to monitor the growth status and nutritional diagnosis of fruit trees. In recent years, domestic and foreign fruit trees remote sensing monitoring has made some progress. The model of red edge spectrum and grape chlorophyll content was established, the RMSE (Root mean square error) $<30 \mathrm{mg} \cdot \mathrm{m}^{-2}$. The original spectrum of apple leaf and the leaf spectrum of wavelet filter, the support vector machine , and partial least squares were used to establish the chlorophyll estimation model [4]. The correlation between original leaf spectrum and first-order differential spectrum of apple leaves and chlorophyll content of apple leaves was analyzed. The leaf chlorophyll regression model was established with the spectral position, vegetation index and spectral area as the variables, respectively. The results showed that the exponential model constructed by blue edge position had higher estimation accuracy[5]. The total nitrogen content of the leaves of pear was combined with the original spectral sensitive band and the first-order differential sensitive band, and the total nitrogen content of the leaves was established by stepwise regression analysis. Finally, the first order differential of the spectrum was determined to participate in the constructed model as the leaf total nitrogen content estimation model [6]. The original spectrum of apple leaf, the first order differential spectroscopy, the principal component analysis method and the stepwise regression analysis method were used to establish the chlorophyll content estimation model [7]. Researchers have made a number of attempts to 
estimate the chlorophyll content of leaves of fruit trees. In the case of remote sensing monitoring of fruit trees, the use of random forest (RF) methods has been rare, and RF has been used as a machine learning method in Agricultural remote sensing field. Construction of Vegetation Index, RF and Artificial Neural Network were used for inversion of winter wheat leaf area index with Environmental Satellite Dat[8]. Based on the RF construction model, the vegetation index was used to estimate the soil and plant analyzer development (SAPD) of the winter wheat using the high score number one satellite data[9]. Establishment of SPAD Inversion Algorithm for Wheat Jointing Stage, Booting Stage and Flowering Stage by RF Regression Algorithm[10]. A hyperspectral model for the determination of leaf area index of apple trees using support vector machine and RF [11]. The potential of RF to estimate the biomass of winter wheat was confirmed by constructing the model by combining the correlation coefficient, gray correlation and bag data importance respectively [12].

Analysis of domestic and foreign research results found that most of the research focused on a single growth period of fruit trees for nutritional diagnosis, resulting in the results of the whole tree growth cycle for the nutritional status of the lack of evaluation criteria and guidance [4], this article is for 2 consecutive years estimation of chlorophyll content in leaves of apple during whole growth period. Most studies use only the chlorophyll-related sensitive bands or only use the vegetation index to model, and there is no comparison between the sensitive bands and the vegetation index.

In summary, based on the original spectral and vegetation indices, the 2 models were compared with the original spectral sensitivity and the vegetation indices respectively. The aim of this study was to apply the RF model to the estimation of chlorophyll content and to select the optimal model for estimating the chlorophyll content of apple leaves in order to provide a guide for the rapid estimation of chlorophyll content.

\section{Materials and Methods}

\subsection{Overview of the study area}

The experiment was carried out from 2012 to 2013 in the apple orchard of Xiazhai Village, Chaoquan Town, Feicheng City, Shandong Province. The line spacing was $5 \mathrm{~m}$, the plant spacing was $3 \mathrm{~m}$, the tree height was about $3 \mathrm{~m}$, the tree trunk was about $0.5 \mathrm{~m}$, and the tree is spindle-shaped. 


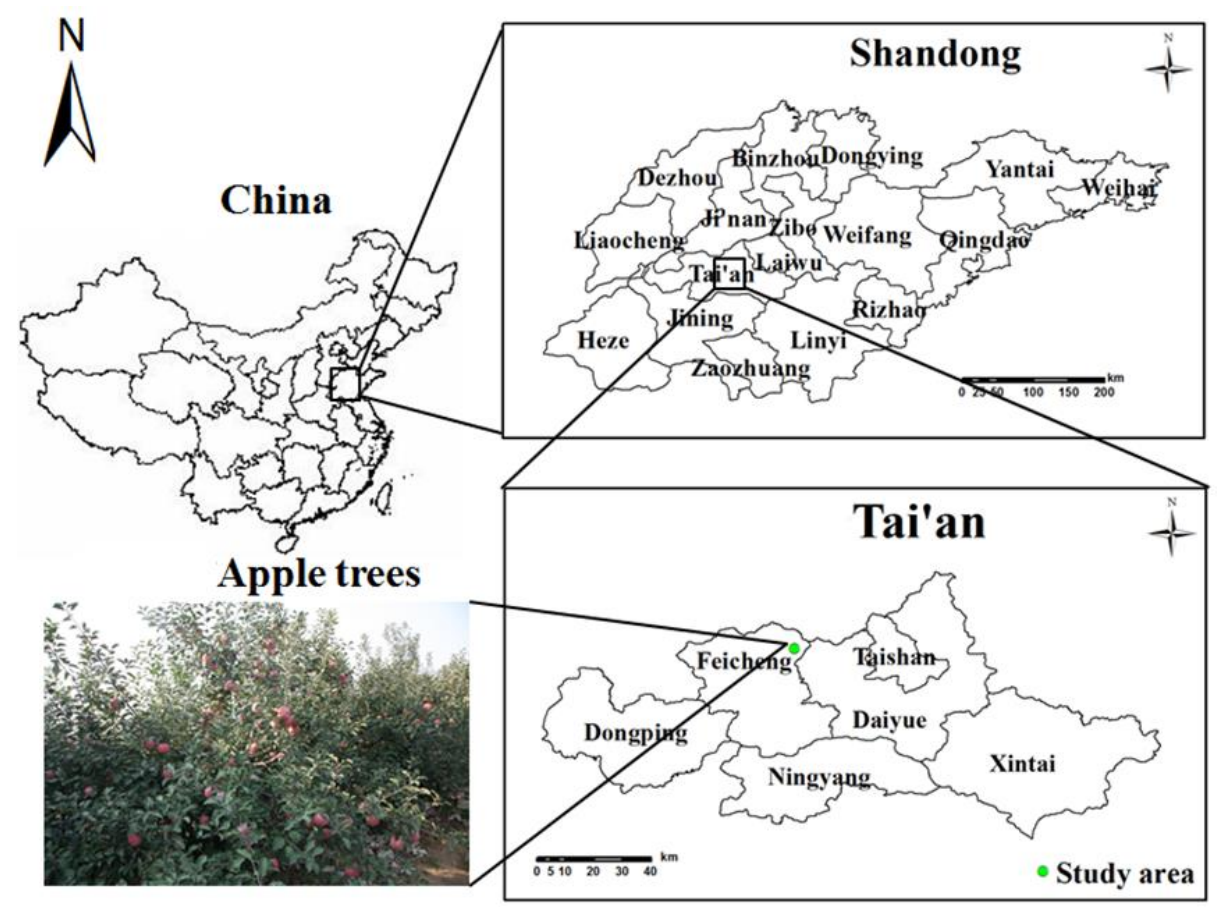

Fig 1 Study area map

\subsection{Leaf sampling and spectrophotometry}

4 leaves were taken for each tree, each leaf in the north, south, east and west direction, respectively. Leaves were sampled and placed in self-styled bags, each tree as a sample and quickly sent back to the laboratory for spectral measurement and chlorophyll sampling. 299 samples were obtained in 2012 including Fushi 220 and Gala 79, and 180 samples were sampled in 2013 including Fushi 135 and Gala 45.

The vein of the leaf should be avoided when the leaves spectrum were measured by ASD hyperspectral spectrometer. The spectral parameters are as follows: the spectral range of the spectrometer is $350 \sim 2500 \mathrm{~nm}$, and the interval is $1 \mathrm{~nm}$. Each leaf was measured in four different positions (twice each side of the veins, and the veins were observed to cover the entire blade during the test), and the average of the four reflectances was taken as the reflectance of the leaf. Before measurement, the standard whiteboard with the blade holder was used to calibrate.

\subsection{Determination of chlorophyll content in apple leaves}

Leaf chlorophyll was sampled at the corresponding position of leaf spectral measurement. And leaf chlorophyll content was measured by chemical method. The four leaves of each tree were punched, and the veins of each leaf were avoided and play 8 holes, covering the entire blade, corresponding to the spectral measurement position. The sample mass is about $0.2 \mathrm{~g}$. The sample was then put in $95 \%$ absolute ethanol solution and allowed to stand in a dark environment for 24 to 48 hours until leaves become white. The chlorophyll content of the apple leaves was determined by ultraviolet spectrophotometer $\left(\mu \mathrm{g} / \mathrm{cm}^{2}\right)$ [13]. The data collected in this study are shown in Table 1, and the statistical characteristics of the chlorophyll data obtained are shown in Table 2.The model was established using the data of chlorophyll content and leaf spectral reflectance $(n=299)$ of apple leaf in 2012 , and the accuracy of RF model with sensitive bands and vegetation indices was verified by the data collected in $2013(\mathrm{n}=180)$.

Table 1 List of data acquisition at each measured time

\begin{tabular}{lllllll}
\hline Date & Growth stage & Growth stage & Fushi Samples & Gala Samples & Chlorophyll & Reflectance \\
\hline
\end{tabular}


content

\begin{tabular}{|c|c|c|c|c|c|c|}
\hline $2012-05-10$ & $\begin{array}{l}\text { Fast-growing period } \\
\text { of shoot }\end{array}$ & $\begin{array}{l}\text { Fast-growing } \\
\text { period of shoot }\end{array}$ & 44 & 16 & $\sqrt{ }$ & $\sqrt{ }$ \\
\hline 2012-07-03 & $\begin{array}{l}\text { Stop-growing period } \\
\text { of shoot }\end{array}$ & $\begin{array}{l}\text { Stop-growing } \\
\text { period of shoot }\end{array}$ & 44 & 15 & $\sqrt{ }$ & $\sqrt{ }$ \\
\hline 2012-08-10 & $\begin{array}{c}\text { Fruit enlargement } \\
\text { period }\end{array}$ & $\begin{array}{l}\text { Fruit maturity } \\
\text { period }\end{array}$ & 44 & 16 & $\sqrt{ }$ & $\sqrt{ }$ \\
\hline 2012-09-20 & $\begin{array}{c}\text { Fruit enlargement } \\
\text { period }\end{array}$ & Leaf color period & 44 & 16 & $\sqrt{ }$ & $\sqrt{ }$ \\
\hline $2012-10-18$ & Fruit maturity & Leaf color period & 44 & 16 & $\sqrt{ }$ & $\sqrt{ }$ \\
\hline 2012 total & & & 220 & 79 & 299 & 299 \\
\hline 2013-04-20 & Blooming period & Blooming period & 27 & 9 & $\sqrt{ }$ & $\sqrt{ }$ \\
\hline $2013-05-25$ & $\begin{array}{c}\text { Fast-growing period } \\
\text { of shoot }\end{array}$ & $\begin{array}{l}\text { Fast-growing } \\
\text { period of shoot }\end{array}$ & 27 & 9 & $\sqrt{ }$ & $\sqrt{ }$ \\
\hline 2013-07-18 & $\begin{array}{l}\text { Fast-growing period } \\
\text { of autumn shoot }\end{array}$ & $\begin{array}{l}\text { Fast-growing } \\
\text { period of } \\
\text { autumn shoot }\end{array}$ & 27 & 9 & $\sqrt{ }$ & $\sqrt{ }$ \\
\hline 2013-08-30 & $\begin{array}{c}\text { Fruit enlargement } \\
\text { period }\end{array}$ & $\begin{array}{c}\text { Fruit maturity } \\
\text { period }\end{array}$ & 27 & 9 & $\sqrt{ }$ & $\sqrt{ }$ \\
\hline $2013-10-25$ & Fruit maturity period & Leaf color period & 27 & 9 & $\sqrt{ }$ & $\sqrt{ }$ \\
\hline 2013 total & & & 135 & 45 & 180 & 180 \\
\hline Total & & & 355 & 124 & 479 & 479 \\
\hline
\end{tabular}

Note: $\sqrt{ }$ represents the data was measured.

Table 2 The chlorophyll content statics of apple leaf

\begin{tabular}{cccccc}
\hline & Sample quantity & & & \multicolumn{2}{c}{ Standard } \\
Samples & & Maximum value & Minimum value & Mean value & deviation \\
\hline Modeling set & 299 & 112.562 & 51.291 & 76.529 & 12.707 \\
Validation set & 180 & 103.518 & 35.677 & 74.367 & 18.133 \\
Total sample & 479 & 112.562 & 35.677 & 75.717 & 14.996 \\
\hline
\end{tabular}

\subsection{Methods}

\subsubsection{Vegetation index selection}

According to previous studies, 25 vegetation indices with good chlorophyll correlation were selected as variables for estimating chlorophyll content, as table 3 shows.

Table 3 Summary of spectral indices related to chlorophyll content

\begin{tabular}{ccc}
\hline Vegetation Index & Formula & Reference \\
\hline Normalized & $\left(R_{680}-R_{430}\right) /\left(R_{680}+R_{430}\right)$ & \\
Pigment Chlorophyll & & \\
Index, (NPCI) & &
\end{tabular}


Simple Ratio

Pigment Index, (SRPI)

Modified

Chlorophyll Absorption

Reflectance

Index,(MCARI)

Modified

Chlorophyll Absorption

Reflectance Index 2,

(MCARI 2)

Transformed

Chlorophyll Absorption

Ratio Index, (TCARI)

MERIS Terrestrial

Chlorophyll index,

(MTCI)

Modified Simple

Ratio2, (MSR 2)

Modified

Normalized Difference

Vegetation Index2,

(MNDVI2)

Normalized

Difference Vegetation

Index2, (NDVI2)

Anthocyanin

Reflectance Index,

(ARI)

Renormalized

Difference Vegetation

Index, (RDVI)

Improved Soil

Adjusted Vegetation

Index, (MSAVI)

Red-Edge Position,

(REP)

Spectral polygon vegetation index, (SPVI)

Simple Ratio,

(SR1)

$$
R_{430} / R_{680}
$$

$$
\left[\left(R_{700}-R_{670}\right)-0.2\left(R_{700}-R_{550}\right)\right]\left(R_{700} / R_{670}\right)
$$

$$
1.2\left[2.5\left(R_{800}-R_{670}\right)-1.3\left(R_{800}-R_{500}\right)\right]
$$

$3\left[\left(R_{700}-R_{670}\right)-0.2\left(R_{700}-R_{550}\right)\left(R_{700} / R_{670}\right)\right]$

$$
\left(R_{754}-R_{709}\right) /\left(R_{709}-R_{681}\right)
$$

$$
\left(R_{750}-R_{445}\right) /\left(R_{705}-R_{445}\right)
$$

$$
\left(R_{750}-R_{705}\right) /\left(R_{750}+R_{705}-2 R_{445}\right)
$$

$$
\left(1 / R_{550}\right)-\left(1 / R_{700}\right)
$$

$$
0.5\left[2 R_{800}+1-\sqrt{\left(2 R_{800}+1\right)^{2}-8\left(R_{800}-R_{670}\right)}\right]
$$

$$
700+40 \frac{\left[\left(R_{670}+R_{780}\right) / 2\right]-R_{770}}{R_{740}-R_{700}}
$$

$$
0.4\left[3.7\left(R_{800}-R_{670}\right)-1.2\left|R_{530}-R_{670}\right|\right]
$$

$$
R_{750} / R_{700}
$$


Vogelmann Indices,

(VOG)

Vogelmann Indices,

(VOG2)

Modified

Chlorophyll Absorptions

Integral, (MCAI)

Derivative Index,

(DI)

Chlorophyll

Absorption Ratio Index,

(CARI)

Double peak

canopy nitrogen index

(DCNI)

Double peak

canopy nitrogen index I

(DCNI I )

\section{Modified MERIS}

terrestrial chlorophyll

index

(MMTCI)

Combined indeIII

Combined indexIV

$$
\left[\left(R_{750}-R_{680}+0.03\right)\left(R_{750}-R_{710}\right)\right] /\left(R_{710}-R_{680}\right)
$$

$$
R_{740} / R_{720}
$$

$$
\left(R_{734}-R_{747}\right) /\left(R_{715}+R_{726}\right)
$$

$\mathrm{A}=$ area of the trapeze between $R_{752}$ and $R_{552}, \mathrm{f}=$ reflectance curve

$$
D_{730} / D_{706}
$$

$$
a=\frac{R_{700}-R_{550}}{150}, b=R_{550} \times a
$$

$$
\left(R_{720}-R_{700}\right) /\left(R_{700}-R_{670}\right) /\left(R_{720}-R_{670}+0.03\right)
$$

$$
\left[\left(R_{750}-R_{670}+0.09\right)\left(R_{750}-R_{700}\right)\right] /\left(R_{700}-R_{670}\right)
$$

\subsubsection{Random forest}

RF is a machine learning algorithm published by American scientist Leo Breiman [35] in 2001. RF based on bootstrap sampling method, extract multiple samples from original samples, use every decision tree to model each bootstrap sample, then combine multiple decision trees to predict, and finally decide the final prediction result by voting.

Bagging [36] is part of RF theory. Assuming that the sample size of the sample set is $\mathrm{N}$, the number of Bootstrap samples taken per time is $\mathrm{n}$, and this part of the sample that is not drawn is called the data outside the bag. These unselected out-of-pocket data can be used to estimate the classification strength of RF single tree, the greater the classification intensity, the smaller the generalization error of RF, the higher the accuracy of classification, and the more accurate prediction [37]. In this study, the importance of the existing vegetation index and the chlorophyll content was analyzed and sequenced using the out-of-pocket data estimation method in RF. The former vegetation index is modeled and estimated as a decision tree. Try to set the number of decision trees to 1000 for the best. 


\subsection{Statistical analysis}

In this paper, we estimate and verify the accuracy of the model selection coefficient $\left(R^{2}\right), R M S E$ as the evaluation criteria. In general, the smaller the RMSE, the greater the coefficient $R^{2}$, indicating the higher the accuracy of the model.

\section{Result and analysis}

\subsection{Correlative analysis of chlorophyll content and spectrum in leaves}

The correlation between chlorophyll content and original spectrum of apple leaves in 2012 is shown in Fig2. There was a significant negative correlation between the leaf chlorophyll content and the original spectrum in the range of 525 $\sim 581 \mathrm{~nm}$ and $693 \sim 735 \mathrm{~nm}$; there was a significant positive correlation in the range of $745 \sim 1350 \mathrm{~nm}$. The correlation coefficients were $-0.46,0.66$ and 0.61, respectively, in the green, red and near-infrared bands, and 554, 708 and $995 \mathrm{~nm}$, respectively, in the bands with the best chlorophyll content. The reflectance of the three bands is used as the input variable for the RF model

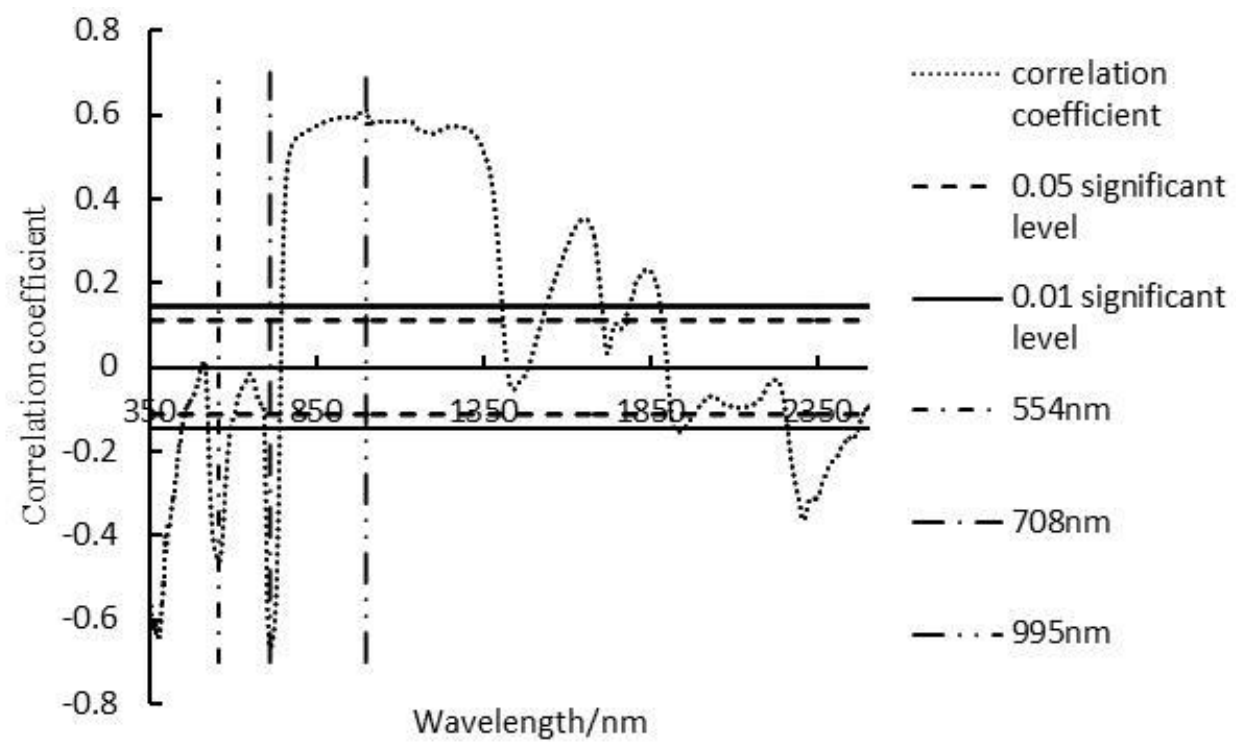

Fig 2 Correlation between spectrum and chlorophyll content

\subsection{RF model based on original spectrum}

The RF spectra were constructed using the original spectral sensitivity bands 554, 708 and 995 nm reflectance $\mathrm{R}_{554}, \mathrm{R}_{708}$ 和 $\mathrm{R}_{995}$, and the corresponding spectra and chlorophyll content in 2013 were verified. Modeling $R^{2}$ is 0.527 , RMSE is $8.728 \mu \mathrm{g} / \mathrm{cm}^{2}$, in table 4 .

Table 4 The accuracy of RF model with original spectrum

\begin{tabular}{cccc}
\hline Model & Variable & $\operatorname{RMSE}\left(\mu \mathrm{g} / \mathrm{cm}^{2}\right)$ & $R^{2}$ \\
\hline $\mathrm{RF}$ & $R_{554}, R_{708}, R_{995}$ & 8.728 & 0.527 \\
\hline
\end{tabular}




\subsection{Screening of vegetation index}

The correlation between chlorophyll content and vegetation index was calculated by using OOB importance estimation method. This paper only considers the top 10 vegetation indices after sorting, because of the operability and simplicity of the model, as shown in Table 5. The vegetation index is sorted by the OOB method.

\begin{tabular}{ccc} 
Table 5 Sequence of relation between vegetation index and chlorophyll an \\
\hline Vegetation index & Importance of OOB & OOB ranking \\
\hline NDVI2 & 6494.599 & 1 \\
MMTCI & 5612.955 & 2 \\
MTCI & 5191.305 & 3 \\
VOG2 & 2805.643 & 4 \\
ARI & 2773.980 & 5 \\
DCNI I & 2277.633 & 6 \\
VOG & 2058.152 & 7 \\
SR1 & 1611.043 & 8 \\
MSR2 & 1587.592 & 9 \\
MNDVI2 & 1562.748 & 10 \\
\hline
\end{tabular}

\subsection{Random forest optimal model}

According to the importance of $\mathrm{OOB}$, the first 10 vegetation indices were selected, and the input number of vegetation index was increased to establish the chlorophyll content estimation model. The modeling results were shown in Table 6. As shown in table 6, when the number of input vegetation indices increases from 1 to 5 , the overall trend of $\mathrm{R}^{2}$ increases and the RMSE decreases. When the number of vegetation indices is $5, \mathrm{R}^{2}$ reaches the maximum, 0.609 , RMSE is the smallest, $7.930 \mu \mathrm{g} / \mathrm{cm}^{2}$. When the number of vegetation indices is $6 \sim 10, \mathrm{R}^{2}$ rises from 0.597 to 0.606 , RMSE decreases from $8.067 \mu \mathrm{g} / \mathrm{cm}^{2}$ to $7.966 \mu \mathrm{g} / \mathrm{cm}^{2}$, but $\mathrm{R}^{2}$ is less than 5 vegetation indices $\mathrm{R}^{2}$ and RMSE are more than 5 vegetation Index of RMSE. Therefore, in the case of selecting the top 10 vegetation indices, the RF model constructed by the first five vegetation indices is the optimal model.

\begin{tabular}{ccc} 
Table 6 Comparison of RF model accuracy with different vegetation indices \\
\hline $\begin{array}{c}\text { Number of vegetation } \\
\text { index }\end{array}$ & RMSE $\left(\mu \mathrm{g} / \mathrm{cm}^{2}\right)$ & $R^{2}$ \\
\hline 1 & 10.305 & 0.380 \\
2 & 9.199 & 0.483 \\
3 & 8.752 & 0.527 \\
4 & 8.765 & 0.525 \\
5 & 7.930 & 0.609 \\
6 & 8.067 & 0.597 \\
7 & 8.046 & 0.599 \\
8 & 8.031 & 0.600 \\
9 & 8.008 & 0.602 \\
10 & 7.966 & 0.606 \\
\hline
\end{tabular}




\subsection{Estimation and verification of chlorophyll content}

RF model verification accuracy was as shown in Figure 3. For RF model based on the original spectrum, $R^{2}$ and $R M S E$ of validation were 0.411 and $14.455 \mu \mathrm{g} / \mathrm{cm}^{2}$, respectively. The validation accuracy of RF model with vegetation indices was $R^{2} 0.843$ and $R M S E 11.034 \mu \mathrm{g} / \mathrm{cm}^{2}$. The results indicate that the RF model based on vegetation index has high accuracy and good stability about the estimation of chlorophyll content. It is proved that the optimal model of vegetation based on vegetation index can be used to estimate the chlorophyll content of apple leaves.

As the figure $3 \mathrm{a}$ shows, estimation ability of RF model with original spectrum was weak. When the measured value was $60 \mu \mathrm{g} / \mathrm{cm}^{2}$ below, the model estimates are overestimated, and when the measured values are greater than 75 $\mu \mathrm{g} / \mathrm{cm}^{2}$, some of the estimates are underestimated, and the estimation value does not change with the increase of the measured value.

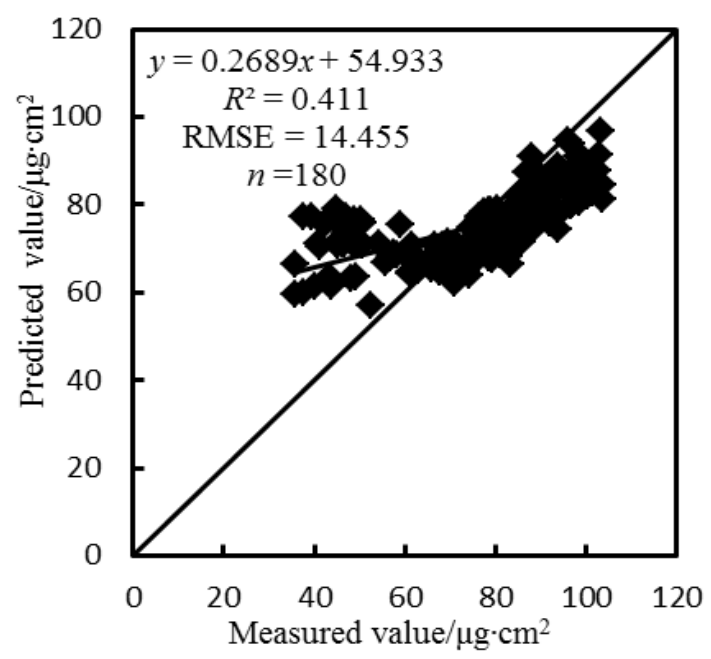

Fig 3a Validation of RF model with original spectrum

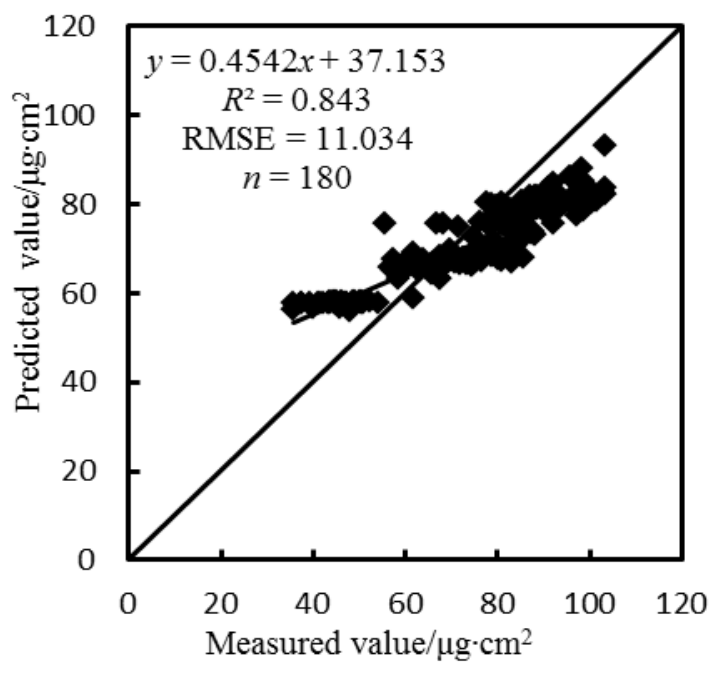

Fig 3bValidation of RF model with vegetation indices

\section{Conclusion}

The RF model based on original spectrum and vegetation indices were established in this paper. The accuracy of RF model with vegetation indices is higher than the accuracy of RF model with original single bands. It can achieve an accurate estimation of apple chlorophyll content.

The accuracy of the RF model based on vegetation index is high. The main reason may be that the RF model based on the original spectrum is used for training data with only three sensitive bands of reflectivity, less model training data, RF models for larger data sets, and less significant for small-scale data.

There are still some shortcomings in this study. Due to climate reasons, the growth period in 2013 is not exactly the same as that in 2012. Because this research only used 2 years' experimental data, if we want to apply it to a large area, we still need more experimental data to improve the accuracy and stability of the model further. And the first collection of data in 2012 is the spring shoot, and the first collection of data in 2013 is the flowering period, while the chlorophyll content in the flowering period is low.

Based on the data collected in 2012 and 2013, the RF model based on the original spectrum and vegetation index was established, respectively and the conclusions as follows.

The sensitive single band $554 \mathrm{~nm}, 708 \mathrm{~nm}, 995 \mathrm{~nm}$, were selected with good correlation between original spectrum and leaf chlorophyll content of the apple. The three band were chosen as variables of RF model.

For modeling accuracy, the $R^{2}$ of RF model with sensitive bands and vegetation indices were 0.527 and 0.609 , the $R M S E$ of that were 8.728 and $7.930 \mu \mathrm{g} / \mathrm{cm}^{2}$, respectively. For validation accuracy, the $R^{2}$ of that were 0.411 and 0.843 , 
and the RMSE of that were 14.455 and $11.034 \mu \mathrm{g} / \mathrm{cm}^{2}$.

The results showed that the estimation accuracy of chlorophyll content in RF model based on vegetation index is higher than that of RF based on the original spectrum, and the leaves chlorophyll content can be estimated more accurately. The RF model can be applied to the estimation of chlorophyll in apple leaves.

\section{Acknowledgments}

This work was supported in part by the National Natural Science Foundation of China $(41601346,41601369$, 41471285,41301475), Beijing Academy of agricultural and Forestry Sciences Innovation Capacity Construction Specific Projects (Grant no. KJCX20170423).

\section{Reference}

1. JIANG JinBao, CHEN Yunhao, HUANG Wenjiang. [Using hyperspectral remote sensing to estimate canopy chlorophyll density of wheat under yellow rust stress].[J]. Spectroscopy and Spectral Analysis, 2010, 30(8):2243-2247..

2. XU XinGang, ZHAO Chunjiang, WANG Jihua, LI Cunjun, LIU Huanjun. Study on relationship between new characteristic parameters of spectral curve and chlorophyll content for rice[J]. Spectroscopy and Spectral Analysis, 2011, 31(1):188-191.

3. Mark S, Anatolya G, Donald R. Nondestructive Estimation of Leaf Chlorophyll Content in Grapes[J]. American Journal of Enology \& Viticulture, 2008, 59(3):299-305.

4. ZHANG Yao, ZHENG Lihua, LI Minzan, DENG Xiaolei, WANG Shicong, JI Ronghua. Construction of apple tree leaves nutrients prediction model based on spectral analysis[J]. Transactions of the Chinese Society of Agricultural Engineering, 2013, 29(8):171-178.

5. LI Minxia. Correlation between apple leaf spectral reflectance and chlorophyll content and leaf total nitrogen[D]. Northwest Agriculture and Forestry University, 2009.

6. LI Ping. Study on modeling total and phosphorus content of Korla Fragrant Pear leaves based on Hyperspectrum by analysis[D]. Xinjiang Agricultural University, 2013.

7. ZHANG Leilei. Hyperspectral Estimation on Chlorophyll and Water Contents in Young Apple Leaves[D]. Shandong Agricultural University, 2013.

8. WANG Liai, ZHOU Xudong, ZHU Xinkai, GUO Wenshan. Inverting wheat leaf area index based on HJ-CCD remote sensing data and random forest algorithm[J]. Transactions of the Chinese Society of Agricultural Engineering, 2016(3):149-154.

9. LI Fenling, WANG Li, LIU Jing, CHANG Qingrui. Remote sensing estimation of SPAD value for wheat leaf based on GF-1 data[J]. Transactions of the Chinese Society of Agricultural Machinery, 2015, 46(9):273-281.

10. WANG Liai, MA Chang, ZHOU Xudong, ZHU Xinkai, GUO Wenshan. Estimation of wheat leaf SPAD value using RF algorithmic model and remote sensing data[J]. Transactions of the Chinese Society of Agricultural Machinery, 2015, 46(1):259-265.

11. HAN Zhaoying, ZHU Xicun, FANG Xianyi, WANG Zhuoyuan, WANG Ling, ZHAO Gengxing, JIANG Yuanmao. [Hyperspectral Estimation of Apple Tree Canopy LAI Based on SVM and RF Regression].[J]. Spectroscopy and Spectral Analysis, 2016, 36(3) 800-805.

12. YUE Jibo, YANG Guijun, FENG Haikuan. Comparative of remote sensing estimation models of winter wheat biomass based on random forest algorithm[J]. Transactions of the Chinese Society of Agricultural Engineering,2016(18):175-182.

13. LICHTENTHALER H K. Chlorophylls and carotenoids: pigments of photosynthetic biomembranes[J]. Methods in Enzymology,1987, 148(34): 350-382.

14. PERIUELAS J, GAMON J A, FREDEEN A L, MERION J, FIELD CB. Reflectance indices associated with physiological changes in nitrogen- and water-limited sunflower leaves $\mathcal{\imath}[\mathrm{J}]$. Remote Sensing of Environment, 1994, 48(2):135-146. 
15. J. PEN-UELAS, I. FILELLA, P. LLORET, F. MUN ${ }^{-}$OZ, M. VILAJELIU. Reflectance assessment of mite effects on apple trees[J]. International Journal of Remote Sensing, 2010, 16(14):2727-2733.

16. DAUGHTRY C S T, WALThall C L, KIM M S, COLSTOUN EBD, LII MM. Estimating Corn Leaf Chlorophyll Concentration from Leaf and Canopy Reflectance[J]. Remote Sensing of Environment, 2000, 74(2):229-239.

17. HABOUDANE D, MILLER J R, PATTEY E, ZARCO-TEJADA PJ, STRACHAN IB. Hyperspectral vegetation indices and novel algorithms for predicting green LAI of crop canopies: Modeling and validation in the context of precision agriculture[J]. Remote Sensing of Environment, 2004, 90(3):337-352.

18. HABOUDANE D, MILLER J R, TREMBLAY N, ZARCO-TEJADA PJ, DEXTRAZE L. Integrated narrow-band vegetation indices for prediction of crop chlorophyll content for application to precision agriculture[J]. Remote Sensing of Environment, 2002 , 81(2):416-426.

19. J. DASH, P. J. CURRAN. The MERIS terrestrial chlorophyll index[J]. International Journal of Remote Sensing, 2004, 25(23):5403-5413.

20. SIMS D A, GAMON J A. Relationships between leaf pigment content and spectral reflectance across a wide range of species, leaf structures and developmental stages[J]. Remote Sensing of Environment, 2002, 81(2-3):337-354.

21. TUCKER C J. Red and photographic infrared linear combinations for monitoring vegetation[J]. Remote Sensing of Environment, 1979, 8(2):127-150.

22. GITELSON A A, MERZLYAK M N, Chivkunova O B. Optical Properties and Nondestructive Estimation of Anthocyanin Content in Plant Leaves[J]. Photochemistry \& Photobiology, 2001, 74(1):38-45.

23. ROUJEAN J L, BREON F M. Estimating PAR absorbed by vegetation from bidirectional reflectance measurements[J]. Remote Sensing of Environment, 1995, 51(3):375-384.

24. QI J, CHEHBOUNI A, HUETE A R, KERR YH, SOROOSHIAN S. A modified soil adjusted vegetation index $2[\mathrm{~J}]$. Remote Sensing of Environment, 1994, 48(2):119-126.

25. GUYOT, G., BARET, F., MAJOR, D.J., 1988. High spectral resolution: Determination of spectral shifts between the red and near infrared. ISPRS Archives, vol. XXVII Part B7, pp. 750-760.

26. VINCINI M, FRAZZI E, ALESSIO P D '. Angular dependence of maize and sugar beet VIs from directional CHRIS/Proba data[J]. 2006.

27. A. A. GITELSON, M. N. MERZLYAK. Remote estimation of chlorophyll content in higher plant leaves[J]. International Journal of Remote Sensing, 1997, volume 18(12):2691-2697.

28. J. E. VOGELMANN, B. N. ROCK, D. M. MOSS. Red edge spectral measurements from sugar maple leaves[J]. International Journal of Remote Sensing, 1993, 14(8):1563-1575.

29. ZARCOTEJADA P J, MILLER J R, NOLAND T L, MOHAMMED GH. Scaling-up and model inversion methods with narrowband optical indices for chlorophyll content estimation in closed forest canopies with hyperspectral data[J]. IEEE Transactions on Geoscience \& Remote Sensing, 2001, 39(7):1491-1507.

30. OPPELT, NATASCHA, MAUSER, WOLFRAM. The chlorophyll content of maize (zea mays) derived with the Airborne Imaging Spectrometer AVIS[J]. 2001.

31. ZARCO-TEJADA P J, PUSHNIK J C, DOBROWSKI S, USTIN SL. Steady-state chlorophyll a, fluorescence detection from canopy derivative reflectance and double-peak, red-edge effects[J]. Remote Sensing of Environment, 2003, 84(2):283-294.

32. KIM M S, DAUGHTRY C S T, CHAPELLE E W (1994). The use of high spectral resolution bands for estimating absorbed photosynthetically active radiation (Apar.). In: Proceedings of the Sixth Symposium on Physical Measurements and Signatures in Remote Sensing. January 17-21, 1994, Val D’ Isure, France, 299

33. CHEN P, Haboudane D, Tremblay N, WANG Jihua, Vigneault P, LI Baoguo. New spectral indicator assessing the efficiency of 
crop nitrogen treatment in corn and wheat[J]. Remote Sensing of Environment, 2010, 114(9):1987-1997.

34. JIN Xiulinag, LI Zhenhai, FENG Haikuan, YANG Guijun. Newly Combined Spectral Indices to Improve Estimation of Total Leaf Chlorophyll Content in Cotton[J]. IEEE Journal of Selected Topics in Applied Earth Observations \& Remote Sensing, 2014, 1(1):4589-4600.

35. BREIMAN Leo. Random Forests[J]. Machine Learning, 2001, 45(1): 5-32.

36. BREIMAN L. Bagging Predictors[J]. Machine Learning, 1996, 24(2):123-140.

37. WOLPERT D H, Macready W G. An Efficient Method To Estimate Bagging's Generalization Error[C]// Santa Fe Institute, 1999:41-55.

38. WANG Huiwen, MENG Jie. Predictive modeling on multivariate liner regression[J]. Journal of Beijing University of Aeronautics and Astronautics, 2007, 33(4):500-504.

39. LI Xuqing, LIU Xiangnan, LIU Meiling, Wu Ling. Random forest algorithm and regional application of spectral inversion model for estimating canopy nitrogen concentration in rice[J]. Journal of Remote Sensing, 2014,18(4):934-945.

40. VERIKAS A, GELZINIS A, BACAUSKIENE M. Mining data with random forests: A survey and results of new tests[J]. Pattern Recognition, 2011, 44(2):330-349. 